\title{
DEVELOPMENT OF HEALTH MONITORING SYSTEM
}

\author{
Kedar Kale \\ Computer Science Department \\ MIT Academy Of Engineering \\ Pune University
}

\author{
Sankeit Dighe \\ Computer Science Department \\ MIT Academy Of Engineering \\ Pune University
}

\author{
Tejas Dhakad \\ Computer Science Department \\ MIT Academy Of Engineering \\ Pune University
}

\begin{abstract}
In India, near about $27 \%$ of the deaths are due to interrupted and delayed health monitoring systems or lack of readily available health resources. It is possible for a patient's health to become critical in a state where a doctor is not available with the patient. In some severe cases, a patient may also lose his life. So, to avoid these life-threatening situations; we are designing a smart system device using an Arduino which monitors patient's health continuously. This system monitors patient's heart rate, body temperature and other vital parameters. Through this system, a doctor can supervise multiple patient's health. The system contains an Arduino interfaced with specialized sensors, which acquires data about important physiological parameters of a patient. The doctors can view the data of a particular patient at any time.
\end{abstract}

Keywords: Arduino, Patient's heart rate, Sensors.

\section{INTRODUCTION}

\section{Motivation}

Delayed medical attention resulted in $27 \%$ of deaths last year in India. The major factors for this delay were negligence or lack of awareness of community. Another reason is that people do not want to take responsibility of a patient or a person in need of urgent medical care.

This delay can be avoided if patients are made to carry a health monitoring system which will alert the user, when the vital signs of the patient go below a certain threshold. Introduction of such a system will ensure the patient gets necessary medical treatment in time.

\section{Objective and Scope}

Following are the objectives of our system:

- To continuously monitor certain vital signs of a patient.

- To Store these values in a secured database.

- To access database at any time.

Successful implementation of the above objectives will ensure an effortless and efficient health experience for the patient.

\section{Problem Statement}

To design and develop Patient Health Monitoring System using Arduino, to continuously monitor a patient's vital signs and store them in a secured location.

\section{LITERATURE SURVEY}

Patient Monitoring System is a process in which a doctor can constantly supervise more than one person, in excess of one parameter at a time in a remote area. Heart beat indicates the soundness of human heart. It helps in assessing the condition of patient's cardiovascular system. Usually, the heart rate which is calculated for normal resting adult males is about to $70 \mathrm{bpm}$ and for adult females is $75 \mathrm{bpm}$.

Body temperature is also a common indication of body condition. Normal human body temperature is $\left(98.6^{\circ} \mathrm{F} \pm\right.$ $0.7^{\circ} \mathrm{F}$ ) and it differs activity of the person as well as place of measurement.

Other parameters also act as good indicators of a patient's health, such as moisture content and salinity levels, blood pressure, breathing patterns.

\section{WHAT IS REMOTE PATIENT HEALTH MONITORING SYSTEM}

Now Recently wireless sensor networks (WSN) play a vital role in the research and technological community, hence resulting in the development of various high-performance smart sensing system. Many new researches are focused at improving quality of human life in terms of health by designing and fabricating sensors which are either in direct contact with the human body (invasive) or indirectly (noninvasive) in contact.

This type of system mainly includes:

1. User interface: A monitor, computer, or Phone, for example, that can give orders to

2. control System.

3. Mode of transmission: Wired connections (example Ethernet) or Wireless (radio waves, infrared, Bluetooth, GSM) etc.

4. Central Controller: It is hardware interface that communicates with user interface between user and electrical components.

5. Sensors: Act as components which are in contact with human body, which are responsible for data acquisition. 


\section{International Journal of Engineering Applied Sciences and Technology, 2019 \\ Vol. 4, Issue 5, ISSN No. 2455-2143 Pages 1-5 \\ Published Online November - December 2019 in IJEAST (http://www.ijeast.com)}

\section{WHY THERE IS A NEED FOR REMOTE PATIENT HEALTH MONITORING}

It greatly increases quality of healthcare. A doctor can assess a patient in a surrounding, which is comfortable and familiar for the patient. Patients are more engaged with their doctors and have a higher tendency to look after their health. It also increases the capacity for doctors to treat more patients, which is financially beneficial for him.

\section{LIMITATIONS}

The main barrier for this system is its cost. An individual's motivation to manage their health is also an important factor. Without the patient's willingness to be an active participant in their care, the system's implementation will likely fail.

The system is highly dependent on an extensive wireless telecommunications infrastructure, which may not be available or feasible in rural areas. Also, since it involves transmission of sensitive patient data across telecommunication networks, information security is a concern.

\section{SYSTEM DESIGN}

Heart rate, body temperature monitoring are very important parameters of human body. Doctors use various kind of medical apparatus like thermometer for checking fever or body temperature, and heart rate monitor for heart rate measurement. In this project, we have built an Arduino based heartbeat monitor which counts the number of heartbeats in a minute. Here we have used a heartbeat sensor module which senses the heartbeat upon putting a finger on the sensor as well as temperature sensor which will record the temperature.

\section{HARWARE COMPONENTS}

1. Arduino Uno

2. LM35 Temperature sensor

3. Pulse rate sensor

4. Resistors

5. Jumper wires

6. Breadboard.

\section{ARDUINO MICROCONTROLLER}

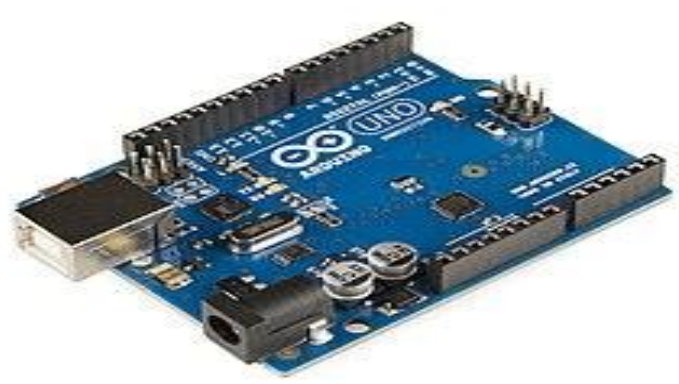

Fig 1 Arduino Board
Arduino Uno is a microcontroller board. It has 14 digital input/output pins (of which 6 can be used as PWM outputs), 6 analog inputs, a $16 \mathrm{MHz}$ quartz crystal, a USB connection, a power jack, an ICSP header and a reset button. It contains everything needed to support the microcontroller; simply connect it to a computer with a USB cable or power it with an AC-to-DC adapter or battery to get started.

\section{LM 35 TEMPERATURE SENSOR}

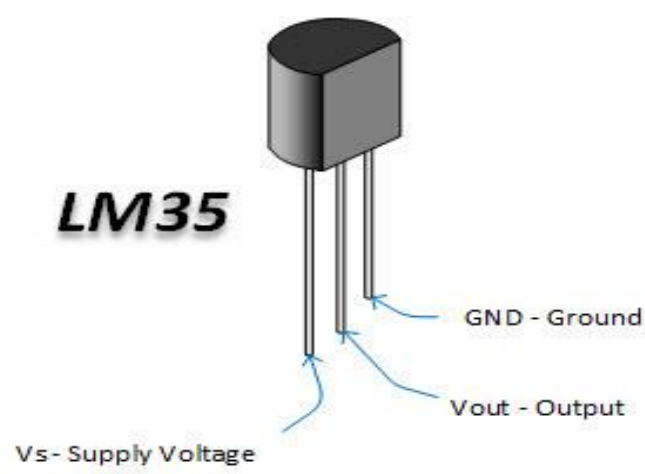

Fig 2 LM35 Temperature Sensor

The LM35 series are precision integrated-circuit temperature devices with an output voltage linearlyproportional to the Centigrade temperature. The LM35 device has an advantage over linear temperature sensors calibrated in Kelvin, as the user is not required to subtract a large constant voltage from the output to obtain convenient Centigrade scaling. The LM35 device does not require any external calibration or trimming to provide typical accuracies for $-55^{\circ} \mathrm{C}$ to $150^{\circ} \mathrm{C}$ temperature range.

\section{PULSE SENSOR}

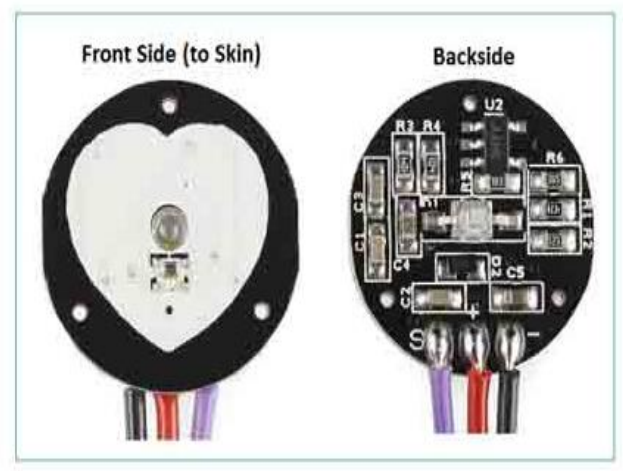

Fig 3 Pulse Sensor

The Pulse Sensor is a plug-and-play heart-rate sensor for Arduino. It can be used by students, artists, athletes, makers, and game \& mobile developers who want to easily incorporate live heart-rate data into their projects. Essence it is an integrated optical amplifying circuit and noise eliminating circuit sensor. 


\section{International Journal of Engineering Applied Sciences and Technology, 2019 \\ Vol. 4, Issue 5, ISSN No. 2455-2143 Pages 1-5 \\ Published Online November - December 2019 in IJEAST (http://www.ijeast.com)}

\section{RESISTORS}

A resistor is a passive two-terminal electrical component that implements electrical resistance as a circuit element. In electronic circuits, resistors are used to reduce current flow, adjust signal levels, to divide voltages, bias active elements, and terminate transmission lines, among other uses.

\section{JUMPER WIRES}

It is an electrical wire, or group of them in a cable, with a connector or pin at each end which is normally used to interconnect the components of a breadboard or other prototype or test circuit, internally or with other equipment or components, without soldering.

\section{SOFTWARE USED}

1. Arduino ide

2. Arduino serial monitor

3. Processing tool

4. Tera term

\section{CiRCUITE DIAGRAM}

1. Pulse Sensor

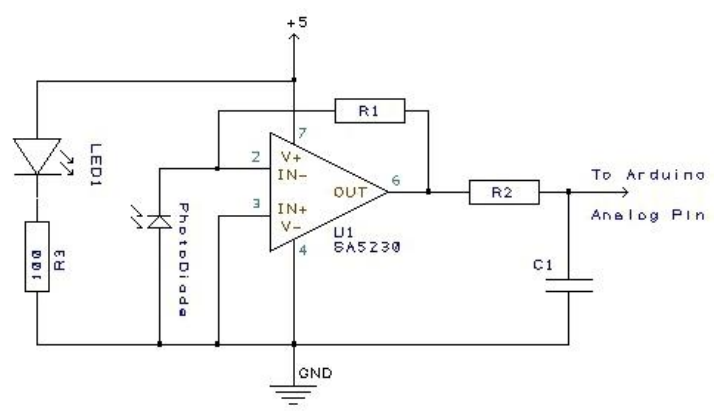

Heartbeat Monitor Circuit Feedback R1=1M

Low Pass Filter $\mathrm{R} 2=100 \mathrm{C} 1=4.7 \mathrm{uF}$

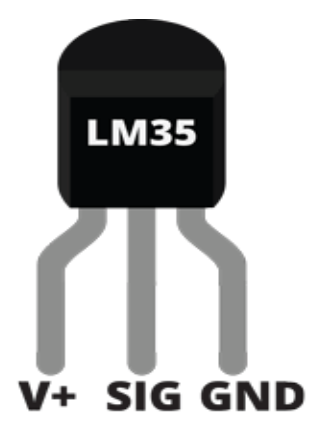

Fig 5 LM35 Pin Configuration

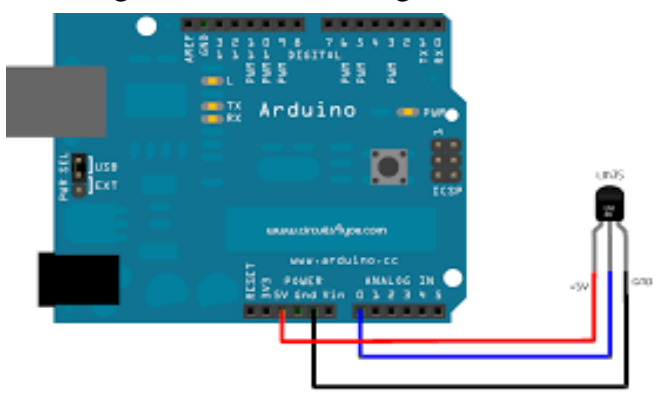

Fig 6 LM35 connections to the Arduino

\section{IMPLEMENTATION DETAILS}

Tools Used

\section{Processing Tool}

This is a useful tool when you want to write both Arduino and Processing programs and have them talk to each other. This works best for communicating simple information from Arduino code to processing code to gain better raw data values for presenting in more than many ways.

\section{Arduino Serial Monitor}

The Serial Monitor is a separate pop-up window that acts as a separate terminal that communicates by receiving and sending Serial Data. Serial Data is sent over a single wire (usually travels over USB) and consists of a series of 1's and 0's sent over the wire. Data can be sent in both directions.

Tera Term

Tera Term is an open source, free, software implemented, terminal emulator application. It can emulate different types of computer terminals, from DEC VT100 to DEC VT382, and it supports telnet, $\mathrm{SSH} 1 \& 2$ and serial port connections. It also has a built-in macro scripting language and some other useful plugins. Tera Term is a useful application, which allows the connection to any remote Telnet or SSH hosts. It sports a clean and crisp layout that is easy to work with.

Working

Calculation of BPM:

Heart beat sensor module's output pin is directly connected to pin 8 of Arduino. Vcc and GND are connected to Vcc and GND.

Then we have calculated total heart beat in a minute by applying the below formula:

Five_pusle_time=time2-time1;

Single_pulse_time $=$ Five_pusle_time $/ 5$;

rate $=60000 /$ Single_pulse_time;

where time 1 is first pulse counter value

time 2 is list pulse counter value

rate is final heart rate.

When the Arduino is connected to the power supply, we use a tool known as processing tool which works best for communicating simple information from Arduino code to processing code to gain better raw data values for presenting in more than many ways. It displays the processed data from the Arduino in a graph which in our project shows the ECG as a continuous waveform along with the BPM of the person. If the BPM increases above a threshold then a push notification is sent to the registered smartphone thorough an email about the danger and need for emergency.

Calculating the Temperature:

A temperature sensor LM35 is also connected to Analog pin A0 of Arduino, which generates 1-degree Celsius temperature on every $10 \mathrm{mV}$ output change at its output pin. 


\section{International Journal of Engineering Applied Sciences and Technology, 2019 \\ Vol. 4, Issue 5, ISSN No. 2455-2143 Pages 1-5 \\ Published Online November - December 2019 in IJEAST (http://www.ijeast.com)}

After getting analog value at analog pin we reads that value using Analog read function and stores that value in a variable. And then by applying given formula converts it in temperature.

float analog value=analog Read(analog pin);

float Temperature $=$ analog value $*$ factor $* 100$

where

factor $=5 / 1023$

analog value $=$ output of temperature sensor

Using the tool names as Tera Term we also display as well as save the data calculated by the Arduino into an excel sheet for further reference.

If the temperature increases above a threshold then a push notification is sent to the registered smartphone thorough an email about the danger and need for emergency.

\section{REsUlts}

Here are the outputs given the Pulse sensor, which shows the heartrate of a patient.

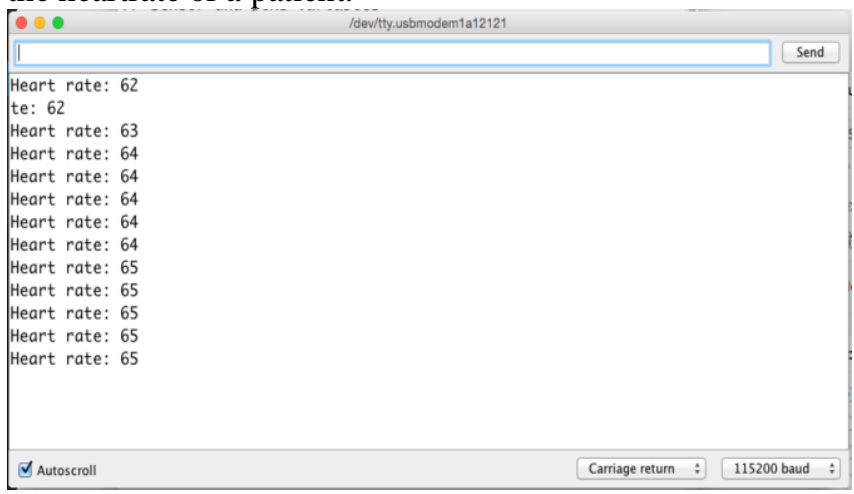

Fig 7 Heartrate output on console

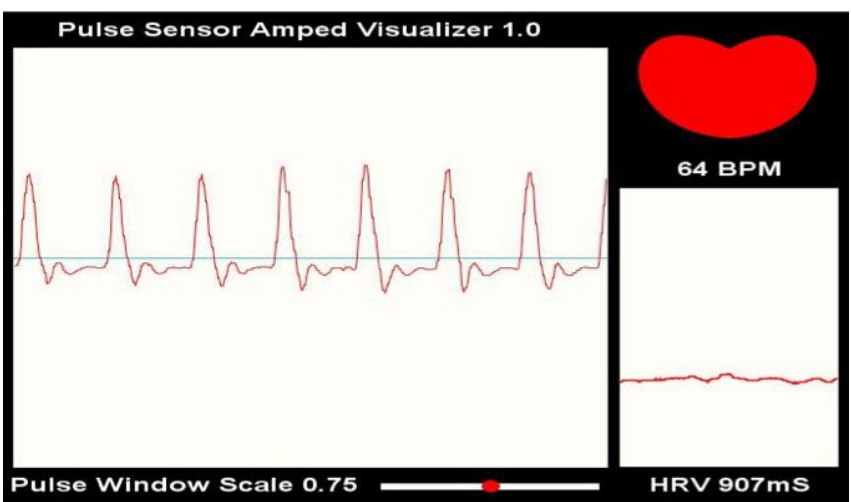

Fig 8 Electrocardiogram of the patient

Output from LM35 which shows the body temperature of the patient.

\begin{tabular}{|l|}
\hline$\infty$ COM13 (Arduino/Genuino Uno) \\
\hline I \\
\hline Temperature $=25.42^{\circ} \mathrm{C}$ \\
Temperature $=25.42^{\circ} \mathrm{C}$ \\
Temperature $=25.42^{\circ} \mathrm{C}$ \\
Temperature $=27.86^{\circ} \mathrm{C}$ \\
Temperature $=28.35^{\circ} \mathrm{C}$ \\
Temperature $=26.88^{\circ} \mathrm{C}$ \\
Temperature $=26.88^{\circ} \mathrm{C}$ \\
Temperature $=26.39^{\circ} \mathrm{C}$ \\
Temperature $=25.90^{\circ} \mathrm{C}$ \\
Temperature $=25.42^{\circ} \mathrm{C}$ \\
\end{tabular}

Fig 9 Body Temperature output on console

\section{CONCLUSION}

A combination of external hardware with the compilation of the code to run the hardware, we have successfully created a portable health monitoring system that reads the pulse rate and temperature of the body.

The scope of our project could be extended further to adding new functionalities like glucometer which will calculate the blood sugar levels and in case of concern, will send a push notification to the user as well as to the doctor without having to travel far distances for pathology labs. Additional functionality of breath analyzer can be added to calculate the ppm of blood alcohol level for people.

\section{REFERENCES}

1. P. W. Digarse and S. L. Patil, (2017) "Arduino UNO and GSM based wireless health monitoring system for patients," International Conference on Intelligent Computing and Control Systems (ICICCS), Madurai, 2017, pp. 583-588

2. Sugathan, G. G. Roy, G. J. Kirthyvijay and J. Thomson, (2013) "Application of Arduino based platform for wearable health monitoring system," IEEE 1st International Conference on Condition Assessment Techniques in Electrical Systems (CATCON), Kolkata, 2013, pp. 1-5.

3. S. Ahmed, S. Millat, M. A. Rahman, S. N. Alam and M. S. R. Zishan, (2015) "Wireless health monitoring system for patients," IEEE International WIE Conference on Electrical and Computer Engineering (WIECON-ECE), Dhaka, 2015, pp. 164-167.

4. M. M. A. Hashem, R. Shams, M. A. Kader and M. A. Sayed, (2010) "Design and development of a heart rate measuring device using fingertip," Computer and Communication Engineering (ICCCE), 2010 International Conference on, Kuala Lumpur, , pp. 1-5.

5. P. F. Binkley, "Predicting the potential of wearable technology," (2003) in IEEE Engineering in Medicine and Biology Magazine, vol. 22, no. 3, pp. 23-27, MayJune 2003 (ISSN 0739-5175) 


\section{International Journal of Engineering Applied Sciences and Technology, 2019 \\ Vol. 4, Issue 5, ISSN No. 2455-2143 Pages 1-5 \\ Published Online November - December 2019 in IJEAST (http://www.ijeast.com)}

6. Compelling Ways to Use Internet of Things in the Field of Medical and Smart Health Care: Kaleem ullah,Munam ali Shah,Sijing zhang, IEEE Journal 2016

7. IReHMo: An Efficient IoT-Based Remote Health Monitoring System for Smart Regions, Ngo Manh Kohi, Karan Mitra, 2015 seventeenth International Conference on E-wellbeing Networking, Application and Services (HealthCom) [4]. Portable based Horne Automation utilizing Internet of Things(IoT), Kumar Mandula, Ram parupalli, E.Magesh, 2015 International Conference on Control, Instrumentation, Communication and Computational Technologies (ICCICCT)

8. Heartbeat checking and ready framework utilizing GSM innovation, Ufaraoh S.U,Oranugo C.O, International Journal of Engineering Research and General Science Volume 3, Issue 4, July-August, 2015 ISSN 2091-2730

9. Pulse checking and heart assault location ,Mamidi manisha, Katakan neeraja, International Journal of Innovations in Engineering and Technology (IJIET) 6. Myocardial dead tissue:

10. https://en.wikipedia.organization/wiki/Myocardial_dead tissue.

11. VivekPardeshi,SaurabhSagar, SwapnilMurmurwar, Pankaj Hage, "Wellbeing Monitoring Systems utilizing IoT and Raspberry Pi 3 - A Review", International Conference on Innovative Mechanisms for Industry Applications.

12. K. Navya, Dr. M. B. R. Murthy, "A Zigbee Based Patient Health Monitoring System", Int. Diary of Engineering Research and Applications Vol. 3, Issue 5, Sep-Oct 2013, pp.483-486

13. Matthew D'Souza, Montserrat Ros, Adam Postula, "Remote Medical Information System Network for Patient ECG Monitoring" Digital System. 